Review

\title{
Role of interferon regulatory factor-mediated signaling in psoriasis
}

\author{
Wen-Ming Wang, Feng Li, Hong-Zhong Jin ${ }^{\bowtie}$ \\ Department of Dermatology, State Key Laboratory of Complex Severe and Rare Diseases, Peking Union Medical College Hospital, Chinese Academy of Medical \\ Science and Peking Union Medical College, Beijing, China. \\ $\triangle$ Corresponding author: Hong-Zhong Jin, M.D. Department of Dermatology, State Key Laboratory of Complex Severe and Rare Diseases, Peking Union \\ Medical College Hospital, Chinese Academy of Medical Sciences and Peking Union Medical College, No.1, Shuaifuyuan Wangfujing Dongcheng District, Beijing \\ 100730, China. Telephone\& Fax: +86 010 69151502; E-mail: jinhongzhong@263.net.
}

(c) The author(s). This is an open access article distributed under the terms of the Creative Commons Attribution License (https://creativecommons.org/licenses/by/4.0/). See http://ivyspring.com/terms for full terms and conditions.

Received: 2021.04.24; Accepted: 2021.09.21; Published: 2021.10.16

\begin{abstract}
Psoriasis is a chronic inflammatory disease that involves both the innate and adaptive immune systems. Type I interferons (IFNs), the production of which is partially regulated by toll-like receptors (TLRs), play an important role in the pathogenesis of psoriasis, especially psoriasis caused by skin trauma, known as the Koebner phenomenon. IFN regulatory factors (IRFs) function in both innate and adaptive immune responses, and their effect is associated with the regulation of type I IFNs. In this review, we focus on recent advances in understanding the expression of TLRs, IRFs, and type I IFNs in psoriasis. We also highlight the interplay among TLRs, IRFs, and type I IFNs.
\end{abstract}

Key words: Psoriasis, Type I Interferons, Toll-Like Receptors, Interferon Regulatory Factors

\section{Introduction}

Psoriasis is a chronic inflammatory disease that commonly manifests as erythematous plaques with adherent silvery scales [1]. The causes of psoriasis are complex, and they include psoriasis autoantigens, the innate and adaptive immune systems, psoriasisassociated susceptibility genes, and environmental factors [1, 2]. Type I interferons (IFNs; IFN- $\alpha$ and IFN- $\beta$ ), in addition to acting as crucial antiviral factors, have also been shown to function in the pathogenesis of psoriasis [3]. The family of IFN regulatory factor (IRF) transcription factors is involved in regulating IFN gene expression [4]. In mammals, nine IRFs have been identified (IRF1-9), all of which play important roles in both innate and adaptive immune responses [5]. Furthermore, IRFs have been found to be associated with the activation and differentiation of immune cells $[5,6]$. In this review, we discuss the interplay among IRFs, type I IFNs, and immune cells in psoriasis and the potential value of targeting these factors for future psoriasis treatments.

\section{Toll-like receptors (TLRs), IRFs, and type I IFNs}

Pattern recognition receptors (PRRs) are crucial for innate immunity, and they help activate the adaptive immune system. PRRs can trigger signaling cascades in response to two sources of stimulation: pathogen-associated molecular patterns (PAMPs) from microbes and endogenous danger-associated molecular patterns (DAMPs) released from necrotic cells. The most notable PRRs are toll-like receptors (TLRs), which play an important role in the production of proinflammatory cytokines, including type I IFNs [7-9].

In humans, there are 11 TLR subtypes, TLR1-11. TLR1, TLR2, TLR4, TLR5, TLR6, and TLR10 are extracellular receptors generally localized at the cell plasma membrane, whereas TLR3, TLR7, TLR8, and TLR9 are localized in the endosomal compartments $[10,11]$. The ligands for TLR10 and TLR11 have not yet been defined [12]. TLRs can recognize a wide range of cell surface components derived from bacteria, viruses, fungi, and parasites; for example, 
TLR1, TLR2, and TLR6 recognize lipoprotein, TLR4 recognizes lipopolysaccharide, TLR5 recognizes flagellin, TLR3 recognizes double-stranded (ds) RNA, TLR7 and TLR8 recognize single-stranded (ss) RNA, and TLR9 recognizes CpG containing unmethylated DNA [11, 13-15].

There are two ways that TLRs can activate adaptive immune responses: through the adaptor MyD88 pathway or through the TRIF pathway. All the TLRs, except for TLR3, signal through the MyD88 pathway. TLR4 can operate through both the TRIF and MyD88 pathways [11]. Previous studies have found that TLRs can trigger the induction of type I IFN and cytokine genes through both the TRIF and MyD88 pathways after recognizing a variety of endogenous DAMPs released from necrotic cells and PAMPs $[16,17]$. As an adaptor protein, MyD88 can lead to gene expression via IRF-1, IRF-5, and IRF-7, whereas TRIF, together with nuclear factor kappalight-chain-enhancer, can lead to the activation of IRF-3 [18-21]. While IRF3 is expressed by a variety of cell types, IRF7 is expressed mainly in plasmacytoid DCs (pDCs). The expression of IRF7 can also be induced by type I IFNs; there is a positive feedback effect between IRF7 and type I IFNs [22-24]. TLR3, TLR4, TLR7, and TLR9 can induce the expression of both IRF3 and IRF7 [23-25]. Additionally, previous studies have revealed that IRF3, IRF5, IRF7, and IRF8 can induce the expression of type I IFN genes [23].

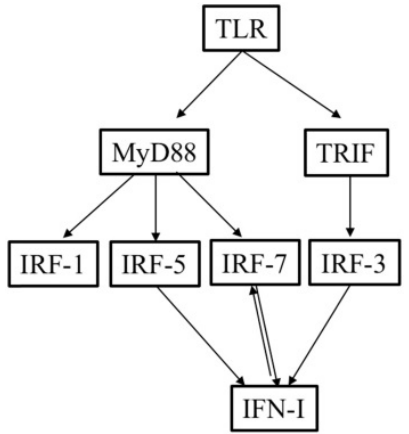

Figure 1. Overview of the relationships among TLRs, IRFs, and type I IFNs.

\section{TLR signaling and psoriasis}

A study conducted on eight samples of normal skin and 15 samples of lesional and non-lesional biopsies from patients with psoriasis demonstrated that TLR1, TLR2, and TLR5 are constitutively expressed in the keratinocytes of normal skin. It also found that cytoplasmic TLR1 is highly expressed on basal keratinocytes in normal skin, whereas nuclear TLR1 is found in the upper layers of both non-lesional and lesional psoriatic keratinocytes. Furthermore, cytoplasmic TLR2 was mainly detected on basal keratinocytes in normal skin but was found to be highly expressed by the upper layer of epidermis in psoriasis lesions. In general, TLR1 and TLR2 were expressed in the upper and middle epidermis of psoriasis lesions. Notably, the expression levels of TLR1 and TLR2 were significantly lower after adalimumab treatment [26].

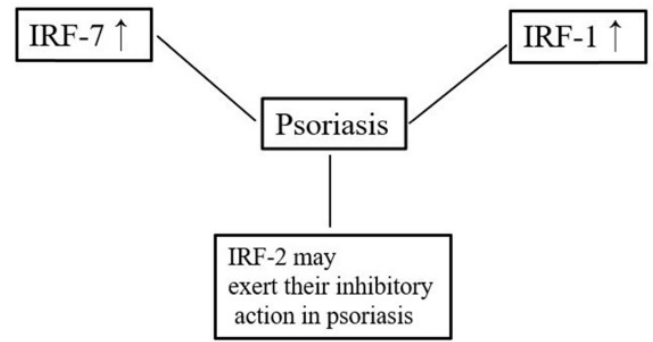

Figure 2. Overview of the relationships between TLR signaling and psoriasis.

The concentration of soluble (s)TLR2 in psoriasis patients, both before and after Goeckerman therapy, was lower than that in healthy controls, whereas the membrane levels of TLR2 on monocytes and granulocytes were significantly upregulated in patients with psoriasis both before and after Goeckerman therapy compared with healthy controls [27]. Consistent with this finding, another study also determined that the TLR2 and TLR4 levels were higher in patients with psoriasis than in control subjects [28]. Furthermore, immunohistochemical staining revealed that TLR4 expression was upregulated in samples from patients with guttate psoriasis compared with samples from individuals with plaque psoriasis or normal skin [29]. The level of TLR7 mRNA in lesional skin from patients with psoriasis was significantly higher than that in healthy controls [30]. Real-time polymerase chain reaction (PCR) revealed that the expression levels of TLR3, TLR5, TLR6, TLR7, TLR9, and TLR10 in lesional skin were higher than those in peripheral blood mononuclear cells (PBMCs) of the same patients with psoriasis [31]. The study also clarified that the levels of TLR1, TLR8, and TLR10 mRNA in PBMCs from patients with psoriasis were significantly higher than those in PBMCs from healthy controls [31]. The expression level of TLR9 in psoriatic lesional skin was higher than that in psoriatic non-lesional skin [32]. In addition, TLR9 also can be induced by wounding in lesional psoriatic skin [33]. The expression level of TLR5 was lower in basal keratinocytes within a psoriasis lesion compared with that in non-lesional psoriatic keratinocytes [34]. Consistent with this, the TLR5 mRNA level was lower in patients with psoriasis than in healthy controls [31]. In conclusion, elevated expression levels of TLR1, TLR2, TLR4, TLR7, and TLR9 may facilitate the occurrence of psoriasis. 


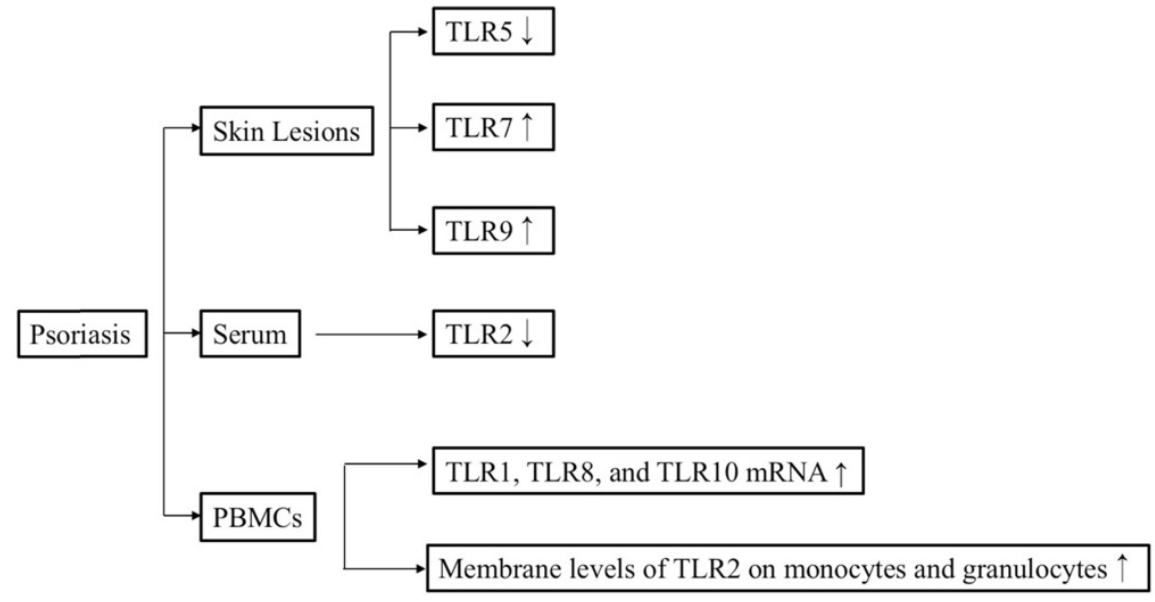

Figure 3. Overview of the relationships between IRFs and psoriasis.

A study conducted on 175 patients with psoriasis and 170 healthy controls found that genotype and allele frequencies for Arg753Gln TLR2 and -1237 T/C TLR9 gene polymorphisms in patients with psoriasis were similar to those in healthy controls. However, the patients with late onset psoriasis were more likely to carry allele $\mathrm{G}$ in the Arg753Gln TLR2 polymorphism, whereas allele $\mathrm{T}$ in the $-1237 \mathrm{~T} / \mathrm{C}$ TLR9 polymorphism was statistically more frequent in the patients with early onset psoriasis [35]. Another study revealed that the TLR2-rs4696480 AA genotype is related to a higher risk of developing psoriasis in the Turkish population [36]. In contrast, the TLR2rs3804099 single nucleotide polymorphism (SNP) was associated with a higher risk of developing psoriasis vulgaris in the Chinese population [37].

\section{IRFs and psoriasis}

IRF1 is one of the transcription factors regulating type I IFN responses. Although SNPs of the IRF1 promoter may be related to the T-helper type 1 (Th1) response in chronic hepatitis C infection [38], studies have found no association between SNPs of the IRF1 promoter and the pathogenesis of psoriasis [39]. IRF1 has been observed throughout the epidermis in both normal skin and psoriatic lesions [40], but one study reported that IRF1 expression is lower in psoriatic lesions than in non-lesions of patients with psoriasis or normal skin. Furthermore, that study also found that the ability of IRF1 and STAT-1a to activate psoriatic keratinocytes was lower than that of normal keratinocytes after IFN-ץ stimulation [41]. In contrast, a different study showed that IRF1 was not differentially expressed between psoriatic lesions and healthy skin [42].

IRF2 can suppress the transcription of type I IFN-inducible genes, and it can also inhibit the function of IRF1 under certain circumstances [43].
Previous studies have classified psoriasis into two subgroups: type 1 and type $2[44,45]$. Type 1 psoriasis refers to cases in which the patient has a low age at onset (early onset) and a positive family history. IRF-2 is considered a potential susceptibility gene for psoriasis, especially type 1 psoriasis $[46,47]$. IRF-2 ${ }^{+/-}$mice (a haploinsufficiency model) showed more severe psoriasis-like dermatitis compared with wildtype mice [48]. IRF2 knockout mice show hyperresponsiveness to type I IFN signaling and exhibit lesions resembling human psoriasis [49]. IRF2 is expressed in the basal cell layer of normal skin and in both the basal and suprabasal cell layers of psoriatic lesions [40]. In contrast, the expression and distribution of IRF2 were found not to differ between individuals with psoriasis and healthy controls [47].

T-helper (Th)17 cells play an important role in the pathogenesis of psoriasis [50]. Previous research demonstrated that T-helper cells from IRF4-deficient mice failed to differentiate into Th17 cells and suggested that IRF4 might play a crucial role in T-helper cell development [51]. IRF5 was demonstrated to be essential for supporting Th1 responses after TLR8 stimulation. Furthermore, the cooperation of IRF5 and NF- $\mathrm{KB}$ is important for supporting Th17 responses [52]. However, although IRF5 is associated with a high risk of developing systemic lupus erythematosus, no relationship between IRF5 polymorphisms and psoriasis per se has been reported [53]. In addition, the expression of IRF7 mRNA in psoriatic lesions is significantly higher compared with that in normal skin [54]. Consistent with this, RNA-seq also confirmed that IRF7 is significantly upregulated in psoriatic lesions compared with normal skin [42]. These findings indicate that IRF might be involved in the pathogenesis of psoriasis. 


\section{Type I IFN signature and psoriasis}

The IFN expression triggered in response to viral infection has been studied extensively. IFNs can be classified into three types: type I IFNs (IFN-a and IFN- $\beta$ ), type II IFN (IFN- $\gamma)$, and type III IFN (IFN- $\lambda$ ) [55]. Type I IFNs and type III IFN can be secreted by several cell types [55], whereas type II IFN is released by activated T cells and NK cells [56]. Previous studies have indicated that IFNs might play important roles in systemic lupus erythematosus, rheumatoid arthritis, and systemic sclerosis [55, 57, 58].

The "Koebner phenomenon" was first described in psoriasis. This condition is not restricted to psoriasis; however, other skin diseases, such as vitiligo, lichen planus, and verruca vulgaris, can also be associated with the Koebner phenomenon. It is still unknown why a cutaneous trauma (e.g., wound, burn, surgical incision, and tattoo) is able to trigger the pathogenesis of psoriasis in healthy skin [59]. Studies have shown that after skin trauma, pDCs can rapidly infiltrate the skin, and IFN-a derived from pDCs may be both necessary and sufficient to trigger psoriasis [60]. In a xenograft murine model, the elevated IFN-a level occurred prior to the development of psoriatic changes [60,61].

Keratinocytes are the main source of IFN- $\beta$ in psoriasis and skin wounds. The IFN- $\beta$ produced by these cells promotes the activation and maturation of pDCs [59, 62]. Higher levels of type I IFN signaling pathway activity were detected in lesional skin compared with non-lesional skin. Additionally, higher mRNA levels of type I IFNs, IFNAR1, and IFNAR2 were also seen in lesional skin than in non-lesional or normal skin [63]. Furthermore, higher levels of IFN-a protein can be detected in patients with active psoriasis than in patients with stationary psoriasis or healthy individuals [63, 64]. Anti-tumor necrosis factor- $\alpha$ (TNF- $\alpha$ ) agents have been used in the treatment of psoriasis for several years. However, there are reports of new-onset or exacerbation of psoriasis occurring after anti-TNF-a therapy; this condition is known as paradoxical psoriasis [65]. Conrad et al. reported that anti-TNF treatment can inhibit pDC maturation, thus leading to the overexpression of type I IFN [66]. These findings indicate that the innate immune system driven by pDC-derived type I IFN may play a crucial role in paradoxical psoriasis. IFN-a therapy for hepatitis C can also induce an exacerbation of preexisting psoriasis or the development of new-onset psoriasis, but this can be resolved by the discontinuation of therapy $[61,67,68]$. Psoriatic lesions can also be induced by the application of topical imiquimod and may be related to the overexpression of IFN-a [69].
Together, these data support a crucial role for type I IFNs in triggering psoriasis.

\section{Conclusion}

As the largest organ in the human body and the first line of defense against pathogens and other threats, the skin is constantly exposed to pathogenic or danger factors from the environment. TLRs can initiate innate immune responses following their recognition of PAMPs or DAMPs. Skin injury or infection can induce the expression of TLRs or stimulate TLRs. TLRs can induce the expression of IRFs through MyD88 pathway or through the TRIF pathway. Furthermore, IRFs can promote the expression of type I IFNs. These studies demonstrated that activation of the TLR-IRF-type I IFN signaling pathway plays an important role in the pathogenesis of psoriasis, especially in the triggering and early phases of this disease. However, understanding of the role of the TLR-IRF-type I IFN signaling pathways in psoriasis is still limited. Thus, further studies are needed to evaluate the exact role and uncover the therapeutic potential of targeting the TLR-IRF-type I IFN signaling pathways in psoriasis.

\section{Acknowledgments}

This study was supported by the National Natural Science Foundation of China (81773331, 82073450).

\section{Competing Interests}

The authors have declared that no competing interest exists.

\section{References}

1. Hawkes JE, Chan TC, Krueger JG: Psoriasis pathogenesis and the development of novel targeted immune therapies. J Allergy Clin Immunol. 2017; 140(3):645-653.

2. Nestle FO, Kaplan DH, Barker J: Psoriasis. N Engl J Med. 2009; 361(5):496-509.

3. Grine L, Dejager L, Libert C, Vandenbroucke RE: An inflammatory triangle in psoriasis: TNF, type I IFNs and IL-17. Cytokine Growth Factor Rev. 2015; 26(1):25-33.

4. Negishi H, Taniguchi T, Yanai H: The Interferon (IFN) Class of Cytokines and the IFN Regulatory Factor (IRF) Transcription Factor Family. Cold Spring Harb Perspect Biol..2018; 10(11).

5. Matta B, Song S, Li D, Barnes BJ: Interferon regulatory factor signaling in autoimmune disease. Cytokine. 2017; 98:15-26.

6. Tamura T, Yanai H, Savitsky D, Taniguchi T: The IRF family transcription factors in immunity and oncogenesis. Annu Rev Immunol. 2008; 26:535-584.

7. Kawai T, Akira S: TLR signaling. Semin Immunol. 2007, 19(1):24-32

8. Beutler BA: TLRs and innate immunity. Blood. 2009; 113(7):1399-1407.

9. Medzhitov R: Recognition of microorganisms and activation of the immune response. Nature. 2007; 449(7164):819-826.

10. Fitzgerald KA, Kagan JC: Toll-like Receptors and the Control of Immunity. Cell. 2020; 180(6):1044-1066

11. Patra MC, Choi S: Recent progress in the development of Toll-like receptor (TLR) antagonists. Expert Opin Ther Pat. 2016; 26(6):719-730.

12. Sun L, Liu W, Zhang LJ: The Role of Toll-Like Receptors in Skin Host Defense, Psoriasis, and Atopic Dermatitis. J Immunol Res. 2019; 2019:1824624. 
13. Kang JY, Nan X, Jin MS, Youn SJ, Ryu YH, Mah S, Han SH, Lee H, Paik SG, Lee JO: Recognition of lipopeptide patterns by Toll-like receptor 2-Toll-like receptor 6 heterodimer. Immunity. 2009;31(6):873-884.

14. Jin MS, Kim SE, Heo JY, Lee ME, Kim HM, Paik SG, Lee H, Lee JO: Crystal structure of the TLR1-TLR2 heterodimer induced by binding of a tri-acylated lipopeptide. Cell. 2007; 130(6):1071-1082.

15. Yoon SI, Kurnasov O, Natarajan V, Hong M, Gudkov AV, Osterman AL, Wilson IA: Structural basis of TLR5-flagellin recognition and signaling. Science. 2012; 335(6070):859-864.

16. Medzhitov R: Toll-like receptors and innate immunity. Nat Rev Immunol. 2001; 1(2):135-145.

17. Kawai T, Akira S: TLR signaling. Cell Death Differ. 2006, 13(5):816-825.

18. Chen JQ, Szodoray P, Zeher M: Toll-Like Receptor Pathways in Autoimmune Diseases. Clin Rev Allergy Immunol. 2016; 50(1):1-17.

19. Akira S, Takeda K: Toll-like receptor signalling. Nat Rev Immunol. 2004; 4(7):499-511.

20. Kawai T, Akira S: Toll-like receptors and their crosstalk with other innate receptors in infection and immunity. Immunity. 2011;34(5):637-650.

21. Kawai T, Akira S: The role of pattern-recognition receptors in innate immunity: update on Toll-like receptors. Nat Immunol. 2010; 11(5):373-384

22. Wu J, Chen ZJ: Innate immune sensing and signaling of cytosolic nucleic acids. Annu Rev Immunol. 2014; 32:461-488.

23. Jefferies CA: Regulating IRFs in IFN Driven Disease. Front Immunol. $2019 ; 10: 325$.

24. Au WC, Moore PA, LaFleur DW, Tombal B, Pitha PM: Characterization of the interferon regulatory factor-7 and its potential role in the transcription activation of interferon A genes. J Biol Chem. 1998; 273(44):29210-29217.

25. Matsuyama T, Kimura T, Kitagawa M, Pfeffer K, Kawakami T, Watanabe N, Kundig TM, Amakawa R, Kishihara K, Wakeham A et al: Targeted disruption of IRF-1 or IRF-2 results in abnormal type I IFN gene induction and aberrant lymphocyte development. Cell. 1993; 75(1):83-97.

26. De Pita O, Nardis C, Lupi F, Luci CA, Frezzolini A, Pallotta S: Modulation of Toll-like receptors in psoriatic patients during therapy with adalimumab. Int I Immunopathol Pharmacol. 2011; 24(1):185-188.

27. Kondelkova K, Krejsek J, Borska L, Fiala Z, Hamakova K, Ettler K, Andrys C: Membrane and soluble Toll-like receptor 2 in patients with psoriasis treated by Goeckerman therapy. Int J Dermatol. 2014; 53(11):e512-517.

28. Garcia-Rodriguez S, Arias-Santiago S, Perandres-Lopez R, Castellote L, Zumaquero E, Navarro P, Buendia-Eisman A, Ruiz JC, Orgaz-Molina J, Sancho J et al: Increased gene expression of Toll-like receptor 4 on peripheral blood mononuclear cells in patients with psoriasis. J Eur Acad Dermatol Venereol. 2013; 27(2):242-250.

29. Seung NR, Park EJ, Kim CW, Kim KH, Kim KJ, Cho HJ, Park HR: Comparison of expression of heat-shock protein 60, Toll-like receptors 2 and 4 , and T-cell receptor gammadelta in plaque and guttate psoriasis. J Cutan Pathol. 2007; 34(12):903-911.

30. El Tawdy AM, Amin IM, Abdel Hay RM, Hassan AS, Gad ZS, Rashed LA: Toll-like receptor (TLR)7 expression in mycosis fungoides and psoriasis: a case-control study. Clin Exp Dermatol. 2017; 42(2):172-177.

31. Gurel G, Sabah-Ozcan S: Evaluation of Toll-like receptor expression profile in patients with psoriasis vulgaris. Gene. 2019; 702:166-170.

32. Morizane S, Yamasaki K, Muhleisen B, Kotol PF, Murakami M, Aoyama Y, Iwatsuki K, Hata T, Gallo RL: Cathelicidin antimicrobial peptide LL-37 in psoriasis enables keratinocyte reactivity against TLR9 ligands. J Invest Dermatol. 2012; 132(1):135-143.

33. Hata TR, Afshar M, Miller J, Two AM, Kotol P, Jackson M, Alexandrescu DT, Kabigting F, Gerber M, Lai Y et al: Etanercept decreases the innate immune wounding response in psoriasis. Exp Dermatol. 2013; 22(9):599-601.

34. Baker BS, Ovigne JM, Powles AV, Corcoran S, Fry L: Normal keratinocytes express Toll-like receptors (TLRs) 1, 2 and 5: modulation of TLR expression in chronic plaque psoriasis. Br J Dermatol. 2003; 148(4):670-679.

35. Zablotna M, Sobjanek M, Purzycka-Bohdan D, Szczerkowska-Dobosz A, Nedoszytko B, Nowicki RJ: The significance of Toll-like receptor (TLR) 2 and 9 gene polymorphisms in psoriasis. Postepy Dermatol Alergol. 2017; 34(1):85-86.

36. Sabah-Ozcan S, Gurel G: The polymorphism rs4696480 in the TLR2 gene is associated with psoriasis patients in the Turkish population. Immunol Lett. 2019; 211:28-32.

37. Shi G, Wang T, Li S, Cheng Y, Sheng P, Fan Y, Zhu K: TLR2 and TLR4 polymorphisms in Southern Chinese Psoriasis Vulgaris patients. J Dermatol Sci. 2016; 83(2):145-147.

38. Saito H, Tada S, Wakabayashi K, Nakamoto N, Takahashi M, Nakamura M, Ebinuma H, Ishii H: The detection of IRF-1 promoter polymorphisms and their possible contribution to T helper 1 response in chronic hepatitis C. J Interferon Cytokine Res. 2002; 22(6):693-700.

39. Van Der Fits L, Kant M, Van Der Wel LI, Prens EP: Polymorphisms in the interferon regulatory factor-1 promoter are not associated with psoriasis and do not influence IFN-alpha-induced Th1 polarization. J Interferon Cytokine Res. 2007; 27(10):841-846.

40. van der Fits L, van der Wel LI, Laman JD, Prens EP, Verschuren MC: Psoriatic lesional skin exhibits an aberrant expression pattern of interferon regulatory factor-2 (IRF-2). J Pathol. 2003; 199(1):107-114.

41. Jackson M, Howie SE, Weller R, Sabin E, Hunter JA, McKenzie RC: Psoriatic keratinocytes show reduced IRF-1 and STAT-1alpha activation in response to gamma-IFN. FASEB J. 1999; 13(3):495-502.

42. Raposo RA, Gupta R, Abdel-Mohsen M, Dimon M, Debbaneh M, Jiang W, York VA, Leadabrand KS, Brown G, Malakouti M et al: Antiviral gene expression in psoriasis. J Eur Acad Dermatol Venereol. 2015; 29(10):1951-1957.

43. Harada H, Fujita T, Miyamoto M, Kimura Y, Maruyama M, Furia A, Miyata $\mathrm{T}$, Taniguchi T: Structurally similar but functionally distinct factors, IRF-1 and IRF-2, bind to the same regulatory elements of IFN and IFN-inducible genes. Cell 1989; 58(4):729-739.

44. Christophers E, Henseler T: Patient subgroups and the inflammatory pattern in psoriasis. Acta Derm Venereol Suppl (Stockh). 1989; 151:88-92; discussion 106-110.

45. Henseler T, Christophers E: Psoriasis of early and late onset: characterization of two types of psoriasis vulgaris. J Am Acad Dermatol. 1985; 13(3):450-456.

46. Foerster J, Nolte I, Schweiger S, Ehlert C, Bruinenberg M, Spaar K, van der Steege G, Mulder M, Kalscheuer V, Moser B et al: Evaluation of the IRF-2 gene as a candidate for PSORS3. J Invest Dermatol. 2004; 122(1):61-64.

47. Parkinson J, Charon C, Baker BS, Powles AV, Rogers S, Caird A, Smedley D, Halford S, Fry L, McCarthy MI: Variation at the IRF2 gene and susceptibility to psoriasis in chromosome 4q-linked families. J Invest Dermatol. 2004; 122(3):640-643.

48. Kawaguchi M, Oka T, Sugaya M, Suga H, Kimura T, Morimura S, Fujita $\mathrm{H}$, Sato S: IRF-2 haploinsufficiency causes enhanced imiquimod-induced psoriasis-like skin inflammation. J Dermatol Sci. 2018; 90(1):35-45.

49. Hida S, Ogasawara K, Sato K, Abe M, Takayanagi H, Yokochi T, Sato T, Hirose S, Shirai T, Taki S et al: CD8(+) T cell-mediated skin disease in mice lacking IRF-2, the transcriptional attenuator of interferon-alpha/beta signaling. Immunity. 2000; 13(5):643-655.

50. Brembilla NC, Senra L, Boehncke WH: The IL-17 Family of Cytokines in Psoriasis: IL-17A and Beyond. Front Immunol. 2018; 9:1682.

51. Brustle A, Heink S, Huber M, Rosenplanter C, Stadelmann C, Yu P, Arpaia E, Mak TW, Kamradt T, Lohoff M: The development of inflammatory $\mathrm{T}(\mathrm{H})-17$ cells requires interferon-regulatory factor 4 . Nat Immunol. 2007; 8(9):958-966.

52. Stein T, Wollschlegel A, Te H, Weiss J, Joshi K, Kinzel B, Billich A, Guntermann C, Lehmann JCU: Interferon regulatory factor 5 and nuclear factor kappa-B exhibit cooperating but also divergent roles in the regulation of pro-inflammatory cytokines important for the development of TH1 and TH17 responses. FEBS J. 2018; 285(16):3097-3113.

53. Sanchez FO, Linga Reddy MV, Mallbris L, Sakuraba K, Stahle M, Alarcon-Riquelme ME: IFN-regulatory factor 5 gene variants interact with the class I MHC locus in the Swedish psoriasis population. J Invest Dermatol. 2008; 128(7):1704-1709.

54. Chen J, Tan Z, Liu H, Liu Z, Wu Y, Li J: Expression of plasmacytoid dendritic cells, IRF-7, IFN-alpha mRNA in the lesions of psoriasis vulgaris. J Huazhong Univ Sci Technolog Med Sci. 2006; 26(6):747-749.

55. Mora-Arias T, Amezcua-Guerra LM: Type III Interferons (Lambda Interferons) in Rheumatic Autoimmune Diseases. Arch Immunol Ther Exp (Warsz). 2020; 68(1):1.

56. Taniguchi $\mathrm{T}$, Ogasawara $\mathrm{K}$, Takaoka A, Tanaka N: IRF family of transcription factors as regulators of host defense. Annu Rev Immunol. 2001; 19:623-655.

57. Barrat FJ, Crow MK, Ivashkiv LB: Interferon target-gene expression and epigenomic signatures in health and disease. Nat Immunol. 2019; 20(12):1574-1583.

58. Ivashkiv LB, Donlin LT: Regulation of type I interferon responses. Nat Rev Immunol. 2014; 14(1):36-49.

59. Zhang LJ: Type1 Interferons Potential Initiating Factors Linking Skin Wounds With Psoriasis Pathogenesis. Front Immunol. 2019; 10:1440.

60. Nestle FO, Conrad C, Tun-Kyi A, Homey B, Gombert M, Boyman O, Burg G, Liu YJ, Gilliet M: Plasmacytoid predendritic cells initiate psoriasis through interferon-alpha production. J Exp Med. 2005; 202(1):135-143. 
61. Afshar M, Martinez AD, Gallo RL, Hata TR: Induction and exacerbation of psoriasis with Interferon-alpha therapy for hepatitis C: a review and analysis of 36 cases. J Eur Acad Dermatol Venereol. 2013; 27(6):771-778.

62. Zhang LJ, Sen GL, Ward NL, Johnston A, Chun K, Chen Y, Adase C, Sanford JA, Gao N, Chensee M et al: Antimicrobial Peptide LL37 and MAVS Signaling Drive Interferon-beta Production by Epidermal Keratinocytes during Skin Injury. Immunity. 2016; 45(1):119-130.

63. Yao Y, Richman L, Morehouse C, de los Reyes M, Higgs BW, Boutrin A, White B, Coyle A, Krueger J, Kiener PA et al: Type I interferon: potential therapeutic target for psoriasis? PLoS One. 2008; 3(7):e2737.

64. Livden JK, Nilsen R, Bjerke JR, Matre R: In situ localization of interferons in psoriatic lesions. Arch Dermatol Res. 1989; 281(6):392-397.

65. Ko JM, Gottlieb AB, Kerbleski JF: Induction and exacerbation of psoriasis with TNF-blockade therapy: a review and analysis of 127 cases. J Dermatolog Treat. 2009; 20(2):100-108.

66. Conrad C, Di Domizio J, Mylonas A, Belkhodja C, Demaria O, Navarini AA, Lapointe AK, French LE, Vernez M, Gilliet M: TNF blockade induces a dysregulated type I interferon response without autoimmunity in paradoxical psoriasis. Nat Commun. 2018; 9(1):25.

67. Mendieta KL, Irfan M, Fernandez Faith E: Interferon-alpha induced psoriasis in a teenager. Pediatr Dermatol. 2018, 35(2):e136-e137.

68. Funk J, Langeland T, Schrumpf E, Hanssen LE: Psoriasis induced by interferon-alpha. Br J Dermatol. 1991; 125(5):463-465.

69. Wu JK, Siller G, Strutton G: Psoriasis induced by topical imiquimod. Australas J Dermatol. 2004; 45(1):47-50. 